\title{
Analysis of Eddy-Current and Magnetic Rail Brakes for High-Speed Trains
}

\author{
Sergey Kitanov and Anatoly Podol'skii*
}

Magnetical Technologies JSC, St. Petersburg, Russia

\begin{abstract}
The investigation of eddy-current and magnetic rail brake structures is described. Comparisons on experimental and computed operating characteristics of eddy-current and magnetic rail brakes for use on a tram-car, on a railroad vehicle, and on a high-speed train are presented. It is demonstrated that a brake built up from permanent magnet pieces that combines both magnetic rail brake and eddy-current brake permits of the most profitable braking action through the whole range of acceptable speeds - from zero (a parking brake) to $350 \mathrm{~km} / \mathrm{hr}$.
\end{abstract}

\section{INTRODUCTION}

Beginning with the rise of rail transport, the braking of a train acts via the wheel. The adhesion force between the wheel and the rail is one of the determining factors when the braking had its greatest impact. However, for high-speed trains (speed to $350 \mathrm{~km} / \mathrm{hr}$ ) with heavier loads on the axle and more complex functions in reduced mounting space, the conventional braking systems relying on the adhesion force between the rail and the wheel are no longer adequate. Firstly, the braking distance increase is unusable. Secondly, the weather dependence of the braking distance is entirely unsuited. Thirdly, it requires of a braking system that shall perform the profitable braking in the event of failure of the brake based on the adhesion force between the wheel and the rail.

In modern engineering, there are demands for braking technologies which have a braking force that is as much as possible independent of the friction coefficient between the wheel and the rail. Moreover, the braking force is bound to be greater than the adhesion force.

At present time, there are two types of brake suitable for high-speed trains: a magnetic rail brake (Fig. 1, segment a) and an eddy-current brake (Fig. 1, segment b).

The braking action of a magnetic rail brake is due to the adhesion force between the brake and the rail, not the wheel and the rail. The adhesion force appears when the brake is attracted to the rail. The magnetostatic attraction force depends on the magnetic field strength and on the contact area of the brake and the rail. The braking force of a magnetic rail brake can be greater than the adhesion force between the wheel and the rail, but it depends crucially on the condition of the rail surface, i. e. on the weather condition.

The braking action of an eddy-current brake stems from the fact that a conducting body slows down when crossing a region of changing magnetic field. The braking force of an eddy-current brake is divorced from adhesion forces between the railroad vehicle and the rail; it does not depend on the

*Address correspondence to this author at the Magnetical Technologies JSC, St. Petersburg, Russia; E-mail: podolsky@rol.ru condition of the rail surface. However, it can be changed when the rail is heated or cooled.

The present paper describes the investigation of eddycurrent and magnetic rail brake structures. We focused attention on a brake that contains permanent magnet pieces and combines both magnetic rail brake and eddy-current brake (Fig. 1, segment c). Such a brake permits the most profitable braking action through the whole range of acceptable speeds - from zero (a parking brake) to $350 \mathrm{~km} / \mathrm{hr}$.

Here, the object is to show through the use of experimental and rated data that

1. the use of brakes that combine both magnetic rail brake and eddy-current brake makes it possible to implement the high-performance braking through the whole range of acceptable speeds, and

2. it is most advantageous to use permanent magnets for such brakes.

The combined brake with permanent magnet pieces essentially enhances the brake power [1]; it is less massive and smaller in dimensions than the analogous brake with electromagnets.

\section{PROBLEMS OF COMPUTERIZED DESIGN OF BRAKES}

Both the magnetic rail brake and the eddy-current brake have long been known [2]. But the magnetic rail brake is explored in-depth more than the eddy-current brake. It is because the design process of the first one is related significantly with the calculation of magnet assembly parameters. A 3-D nonlinear problem of magnetostatics should be solved with either electromagnets or permanent magnet pieces as magnetic field sources. Such problems are solved successfully with the aid of available computational techniques and computer programs. An additional point to emphasize is that an experimental verification of rated results turns out to be simpler for magnetic rail brakes than for eddy-current brakes.

When designing eddy-current brakes an engineer is led to solve more complex problems. 
He has to calculate

1. the magnetic field source parameters (it is similar to the corresponding problem of magnetic rail brake design),

2. the depth of magnetic field penetration the rail (it is similar to the corresponding problem of magnetic rail brake design because the fact that the height of the head of the rail is finite and should be taken into account in both cases),

3. eddy current trajectories within the head of the rail;

4. the superseding of magnetic field of the field source from the head of the rail by magnetic field of eddy current,

5. the distribution of the magnetic field that refers to the response of the magnetic field of eddy current (the magnetic field of the eddy current affects the magnetic state and thus the field distribution of the whole magnet assembly).
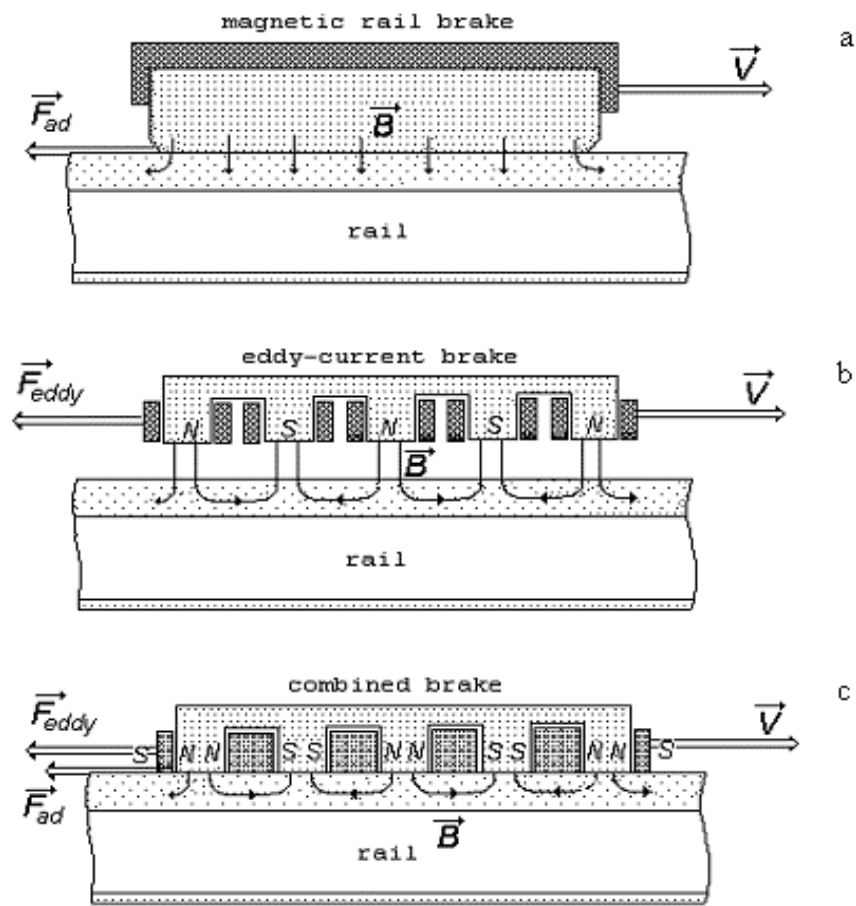

$\vec{V} \quad$ - the vehicle speed:

$\vec{F}_{\text {ad }}$ - the adhesion-produced braking force;

$\vec{F}_{\text {eddy }}$ - the eddy-current-produced braking force;

$\vec{B} \quad$ - the magnetic field induction.

- soft steel;

洨网 - coil;

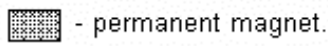

Fig. (1). Three types of rail brakes.

Problems 3, 4, and 5 may be considered as separate with great caution because corresponding processes interact with each other and the magnetic field strength value and eddy current density value vary with time and place.

The examples are known applications of approximate computation procedures to the analysis of brakes [3, 4]. However, the general technique for brake design is nonexistent.
We have devised the computer engineering analysis procedure for both magnetic rail brake and eddy-current brake structures. The potentialities of the computer-aided design software VISAGE [5] are exploited in the process. The computational technique is based on the solution of the integral equation for magnetization in a 3-D inhomogeneous media [6].

The analysis of actual brake structures (described in papers and original) performed with the aid of this procedure has shown good agreement between computation and experiment. As there are reasons to assume that our procedure is adequate, we analyze the variety of hypothetical structures of magnetic rail brakes and eddy-current brakes. Some regular trends relative to deciding between brake types and setting parameters are found that should make the design process more successful.

To validate the suitability of the software VISAGE for the analysis of a brake with combined magnetic rail brake and eddy-current brake structure we consider experimental data and appropriate results of computations for the magnetic rail brake and the eddy-current brake separately.

\section{A CORRELATION BETWEEN EXPERIMENTAL AND COMPUTED CHARACTERISTICS OF BRAKES}

\section{The Magnetic Rail Brake Built Up from Permanent Magnet Pieces [7]}

The brake is composed of a set of brake switchable shoe elements of soft steel. In operation, it is lowered in the direction of the adjacent rail. An individual element in the "on" and "off" positions is shown in Fig. (2). The complete brake contains fifteen such elements.

The magnet pole is $12 \mathrm{~mm}$ lengthwise of the rail and 64 $\mathrm{mm}$ transversely. The constant pole separation is $12 \mathrm{~mm}$. The total length of the brake is $1.6 \mathrm{~m}$.
A

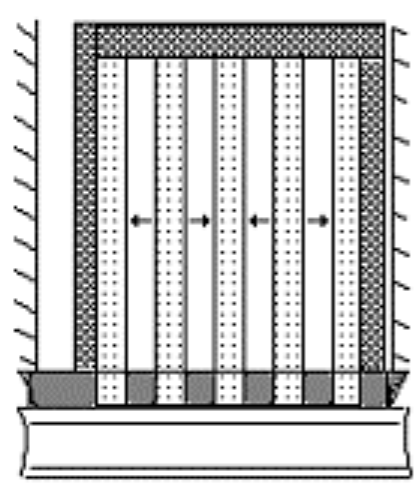

日

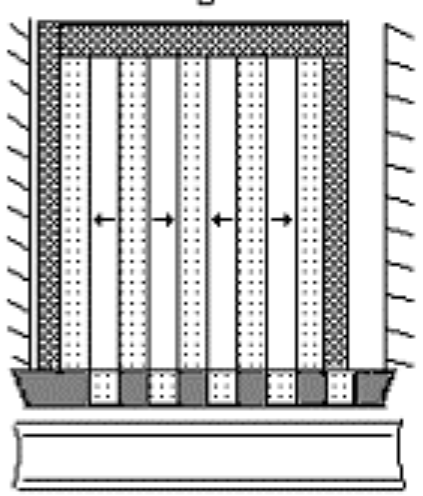

Fig. (2). A magnetic rail brake built up from permanent magnet pieces: (A) the state of switching "on", (B) the state of switching "off".

Measurements of the braking force were taken up to speed value $100 \mathrm{~km} / \mathrm{hr}$. Our analytic computation procedure under test carried out with data presented in [7] shows that the eddy current component of the braking force is negligible and can be ignored. The adhesion-produced braking effect was computed with regard to the empirical relationship between speed and friction coefficient: 
$k_{f r}^{V}=k_{f r}^{0} \times \frac{V+100}{5 V+100}$

where: $V$ is the train speed $(\mathrm{km} / \mathrm{hr})$,

$k_{f r}^{0}$ is the friction coefficient at the speed value close to zero,

$k_{f r}^{V}$ is the friction coefficient at the speed value $V$.

This expression results from the processing of a great quantity of examinations of braking process of trains on railways of the USSR.

In addition, the results of measurements of the friction coefficient as a function of the speed in the range between zero and $300 \mathrm{~km} / \mathrm{hr}$ are presented in [8].

The values computed with (1) and these taken from [8] are presented in Table $\mathbf{1}$.

Table 1. The Speed Dependence of the Friction Coefficient

\begin{tabular}{|c|c|c|c|c|c|c|c|}
\hline $\mathbf{V}, \mathbf{k m} / \mathbf{h r}$ & $\mathbf{0}$ & $\mathbf{5 0}$ & $\mathbf{1 0 0}$ & $\mathbf{1 5 0}$ & $\mathbf{2 0 0}$ & $\mathbf{2 5 0}$ & $\mathbf{3 0 0}$ \\
\hline \hline $\mathbf{k}[\mathbf{8}]$ & 0.200 & 0.110 & 0.078 & 0.060 & 0.048 & 0.040 & 0.035 \\
\hline $\mathbf{k}[\mathbf{1}]$ & 0.200 & 0.090 & 0.067 & 0.060 & 0.054 & 0.052 & 0.050 \\
\hline
\end{tabular}

The results of the measurements [7] and of the computations of braking force values for $k_{f r}^{0}=0.1$ are presented in Fig. (3).

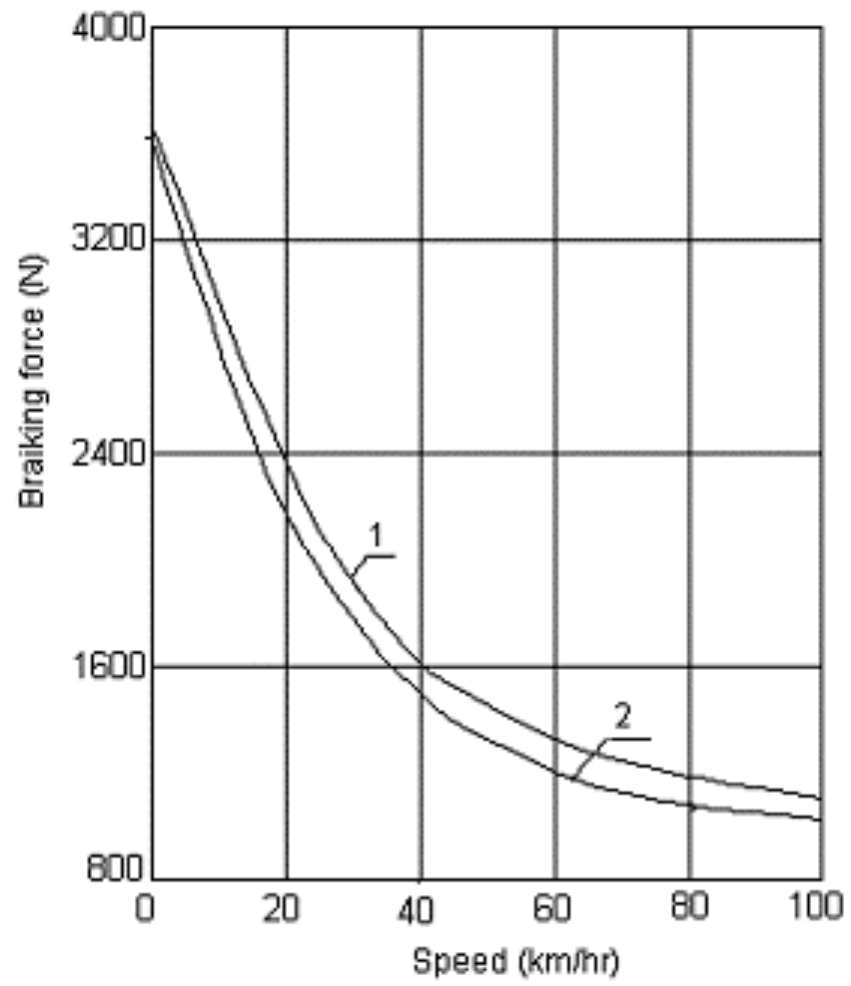

Fig. (3). The computed (1) and the experimental (2) braking force values related to the brake presented in Fig. (2).

Referring to Fig. (3), the computation of the operating characteristics of the magnetic rail brake by the procedure under test using the empirical relationship (1) describes the speed-relationship of braking force adequately. In what follows we use the formula (1) when calculating the adhesionproduced component of the braking force.

Relations presented in Fig. (3) reinforce the statement that the eddy-current component of the braking force has an insignificant effect.

It follows from Fig. (3) that the empirical expression (1) for the friction coefficient as a function of the speed is valid for a magnetic rail brake based on permanent magnets too.

So in what follows we use the empirical relation (1) to compute the braking force.

\section{The Eddy-Current Brake Built Up from Permanent Magnet Pieces}

The brake (Figs. 4,5) is composed of eight magnet assemblies containing permanent magnet pieces and control electromagnets. The magnet pole is $40 \mathrm{~mm}$ in length of the rail and $75 \mathrm{~mm}$ transversely. The constant pole separation is $10 \mathrm{~mm}$. The total length of the brake is $400 \mathrm{~mm}$. In operation, the brake was lowered in the direction of the adjacent rail; thus, there were both eddy-current-produced and adhesion-produced braking processes. The computations that were confirmed by the measurements at the state of rest showed that the magnetic field induction value at the pole of the magnet assembly is $1.5 \mathrm{~T}$ given the contact of the brake and the rail.

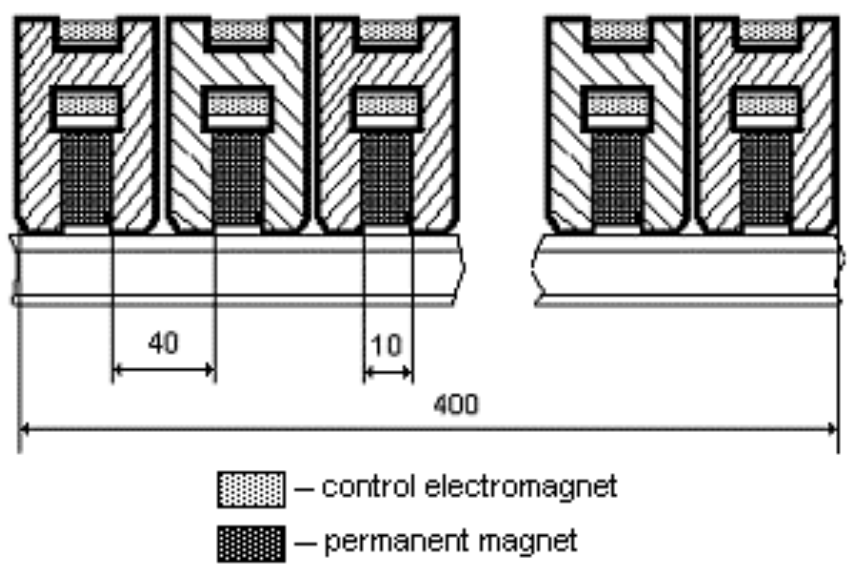

Fig. (4). The brake with combined magnetic rail brake and eddycurrent brake structure.

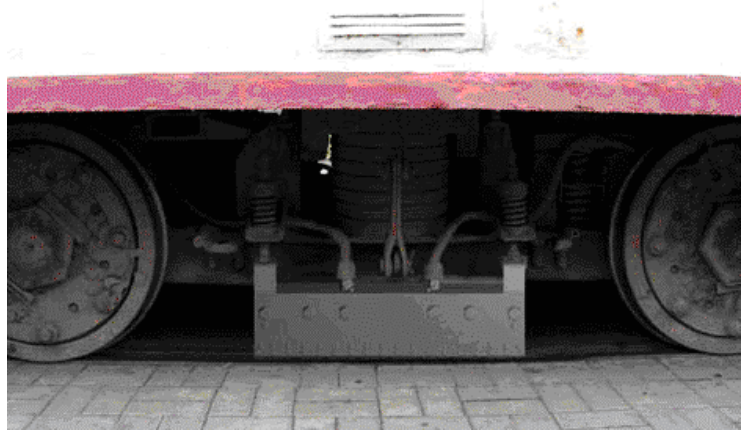

Fig. (5). The brake for a tram-car that combines both magnetic rail brake and eddy-current brake. 
For comparison, on trials two standard magnetic rail brakes each $1 \mathrm{~m}$ long (Fig. 1, segment a, Fig. 6) executing adhesion-produced braking only and two brakes that contain permanent magnet pieces and combine both magnetic rail brake and eddy-current brakes (Fig. 5) outlined above were mounted on a tram-car of mass $20 \mathrm{t}$. The braking process was carried out in turn through two magnetic rail brakes and two eddy-current brakes at the same railway sections under the same weather conditions.

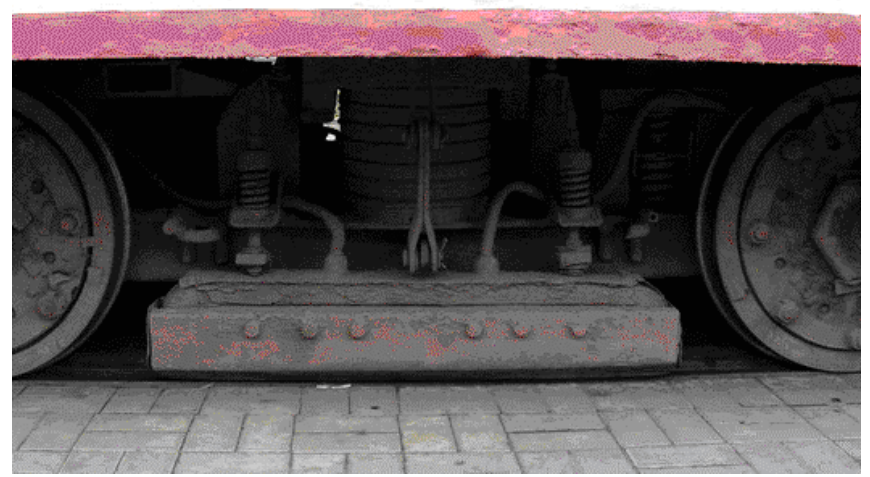

Fig. (6). Magnetic rail brake for a tram-car.

Fig. (7) shows the experimental time-relationships of speed and deceleration during the braking process caused by the action of two magnetic rail brakes (Fig. 6). One can observe the increase of deceleration value that is inherent in adhesion-produced braking process and conditioned, in the first place, by the switching "on" the brake and, in second place, by the rise of the friction coefficient as the speed comes to be lesser. Besides, the fact that the timerelationship of speed curve is convex up is noteworthy. It is also inherent in adhesion-produced braking process. We emphasize that the braking distance value is $170 \mathrm{~m}$ in this situation whereas it would be $110 \mathrm{~m}$ at constant deceleration value $0.38 \mathrm{~m} / \mathrm{s}^{2}$ as one can see from Fig. (7).

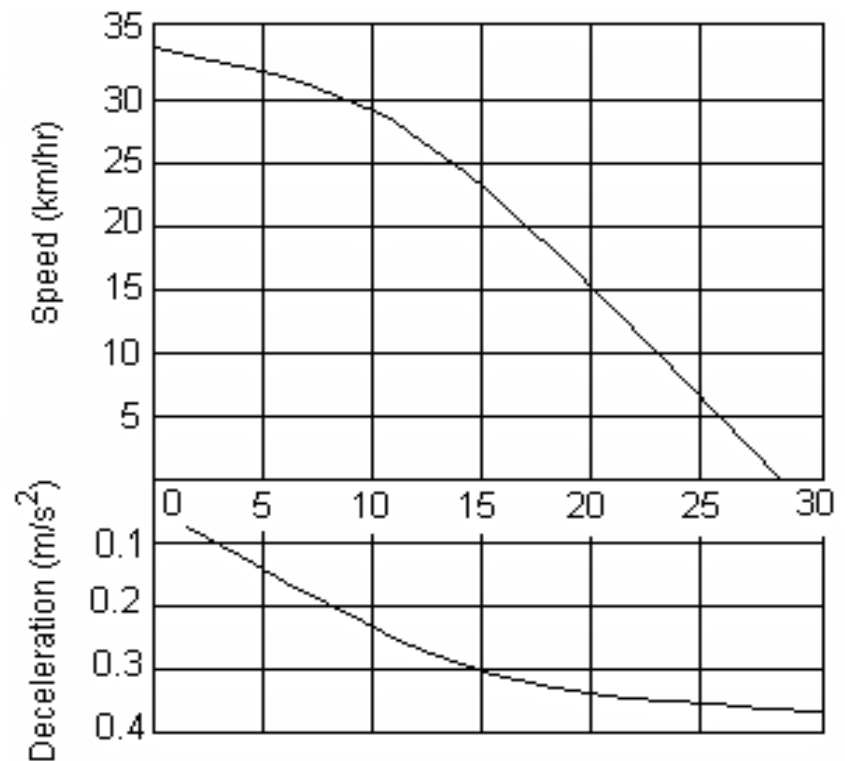

Time (s)

Fig. (7). The experimental time-relationships of speed and deceleration during the tram-car braking process caused by the action of two magnetic rail brakes.
Notice that the deceleration value at the beginning of the braking process at the speed value $35 \mathrm{~km} / \mathrm{hr}$ and the increase of the deceleration value agrees well with the expression (1).

Indeed, the friction coefficient and the braking force values at the speed value $35 \mathrm{~km} / \mathrm{hr}$ are almost half as great as these at zero speed value.

Fig. (8) shows the experimental (1) and the computed (2) time-relationship curves of speed and deceleration in case if the braking process of the tram-car is carried out through the two eddy-current brakes only (Fig. 5). The electrical and mechanical values of the parameters for eddy-current brake computation were presented in Table 2 .

Table 2. The Electrical, Magnetic and Mechanical Parameters of Eddy-Current Brake Computations

\begin{tabular}{|l|c|}
\hline \multicolumn{1}{|c|}{ Parameter (SI unit) } & Value \\
\hline \hline Saturation induction of rail $(\mathrm{B}, \mathrm{T})$ & $\mathbf{1 . 5}$ \\
\hline Residual induction of permanent magnet $(\mathrm{B}, \mathrm{T})$ & $\mathbf{1 . 0}$ \\
\hline Electrical conductivity of rail $\left(\sigma, \Omega^{-1} \mathrm{~m}^{-1}\right)$ & $\mathbf{2 \cdot 1 0 ^ { \mathbf { 6 } }}$ \\
\hline Air-gap $(\mathrm{g}$ m) & $\mathbf{0 . 0}$ \\
\hline Effective rail width $\left(\mathbf{b}_{\mathbf{m}}, \mathbf{m}\right)$ & $\mathbf{0 . 0 6}$ \\
\hline
\end{tabular}

As one can see from Fig. (8), the characteristic properties of eddy-current-produced braking process are

1. the rapid increase of deceleration value conditioned by the switching "on" the brake,

2. the near-exponential decrease of deceleration to the value governed by adhesion-produced braking process only.

Correspondingly, there is a small convex portion of the time-relationship of speed curve, and this portion gives way to a concave one. The computing curve that does not take into account the brake switching "on" process is convex. We emphasize that the braking distance value is $32 \mathrm{~m}$ in this situation whereas it would be $38 \mathrm{~m}$ at constant deceleration value $0.2 \mathrm{~m} / \mathrm{s}^{2}$ as one can see from Fig. (8).

As it is generally known that the deceleration is the time derivative of the speed. The curve 1 in the upper segment of Fig. (8) that represents the experimental time-relationship of speed involves two portions. The first portion is convex and parabolic-like; the second one is concave and hyperbola-like.

Fig. (9) shows the experimental and the computed timerelationships of speed and deceleration during the eddycurrent-produced braking process and the experimental time relationships of speed and deceleration during the braking process caused by the action of magnetic rail brakes. The measurements were taken under the changed weather conditions, and therefore the friction coefficient falls approximately in half. As one can see from Fig. (9), the eddy current braking effect becomes more pronounced at the speed value $50 \mathrm{~km} / \mathrm{hr}$ than at the speed $14 \mathrm{~km} / \mathrm{hr}$ (Fig. 8). Indeed, the measured braking distance value is $520 \mathrm{~m}$, the computed one is $490 \mathrm{~m}$. The braking distance value referred to the adhesion-produced braking process is equal to $750 \mathrm{~m}$ when con- 
ventional electromagnet rail brakes operate each $1 \mathrm{~m}$ long (Fig. 9).

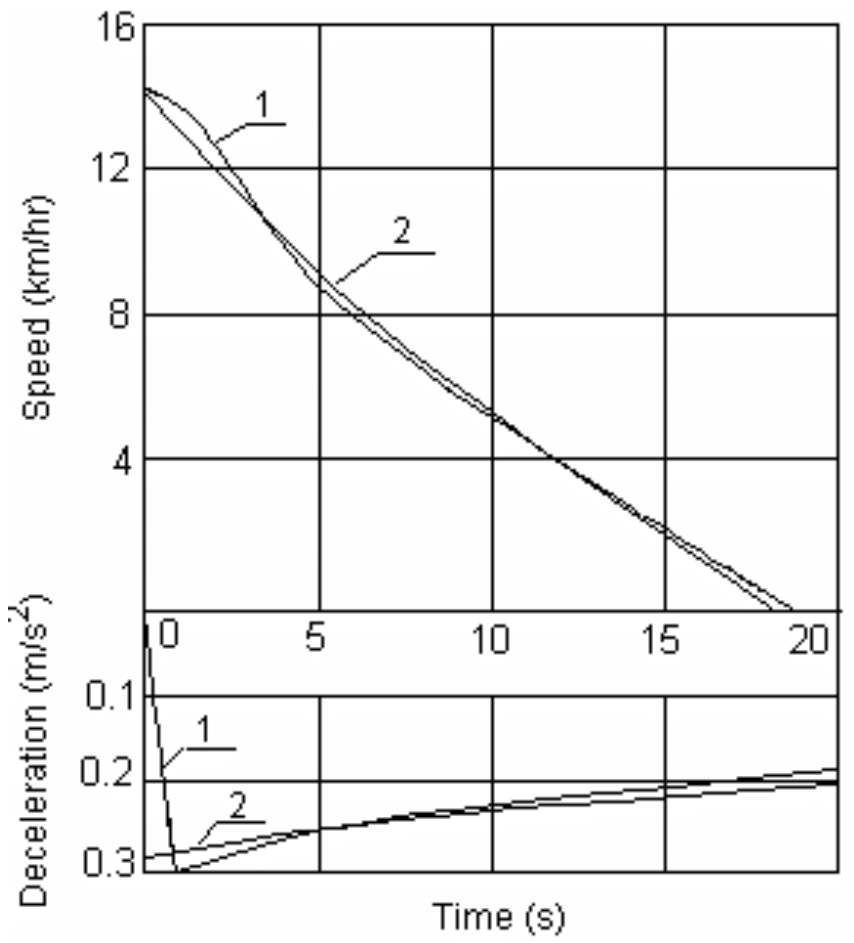

Fig. (8). The experimental (1) and the computed (2) timerelationships of speed and deceleration during the tram-car braking process caused by the action of two eddy-current brakes.

As one can see from Fig. (8) and Fig. (9), the agreement between experimental and computed data may be considered as adequate in these cases too.

\section{The Eddy-Current Brake Manufactured By Knorr- Bremse GmbH $[4,9,8]$}

The paper [4] includes the information (we present it in Fig. (10) and Table 3) that makes it possible to calculate the operating force characteristics of the eddy-current rail brake of Knorr-Bremse GmbH.

Fig. (11) shows the experimental data from [4] and our computation results obtained for eddy current braking force relying on Table $\mathbf{3}$. A correlation was made between experimental and computed data. It demonstrates that the computation procedure under test gives conservatives braking force values for speed values up to $50 \mathrm{~km} / \mathrm{hr}$ and adequate braking force values for greater speed values for the eddy-current brake. A gap between computed and observed braking force values related to small speed values is seemingly explicable, among other things, on the basis of the conjecture that the real electric conduction value of rail material is greater than one using in computation. However, the available experimental data are not full to get the conclusion.

Published electrical conduction values have the wide scatter: from $1.5 \cdot 10^{6} \Omega^{-1} \mathrm{~m}^{-1}$ to $4 \cdot 10^{6} \Omega^{-1} \mathrm{~m}^{-1}$ [10], from $7 \cdot 10^{6}$ $\Omega^{-1} \mathrm{~m}^{-1}$ to $8 \cdot 10^{6} \Omega^{-1} \mathrm{~m}^{-1}$ [11], $2 \cdot 10^{6} \Omega^{-1} \mathrm{~m}^{-1}$ [4]. It has been found experimentally that adequate values may run between $1.5 \cdot 10^{6} \Omega^{-1} \mathrm{~m}^{-1}$ and $2 \cdot 10^{6} \Omega^{-1} \mathrm{~m}^{-1}$.

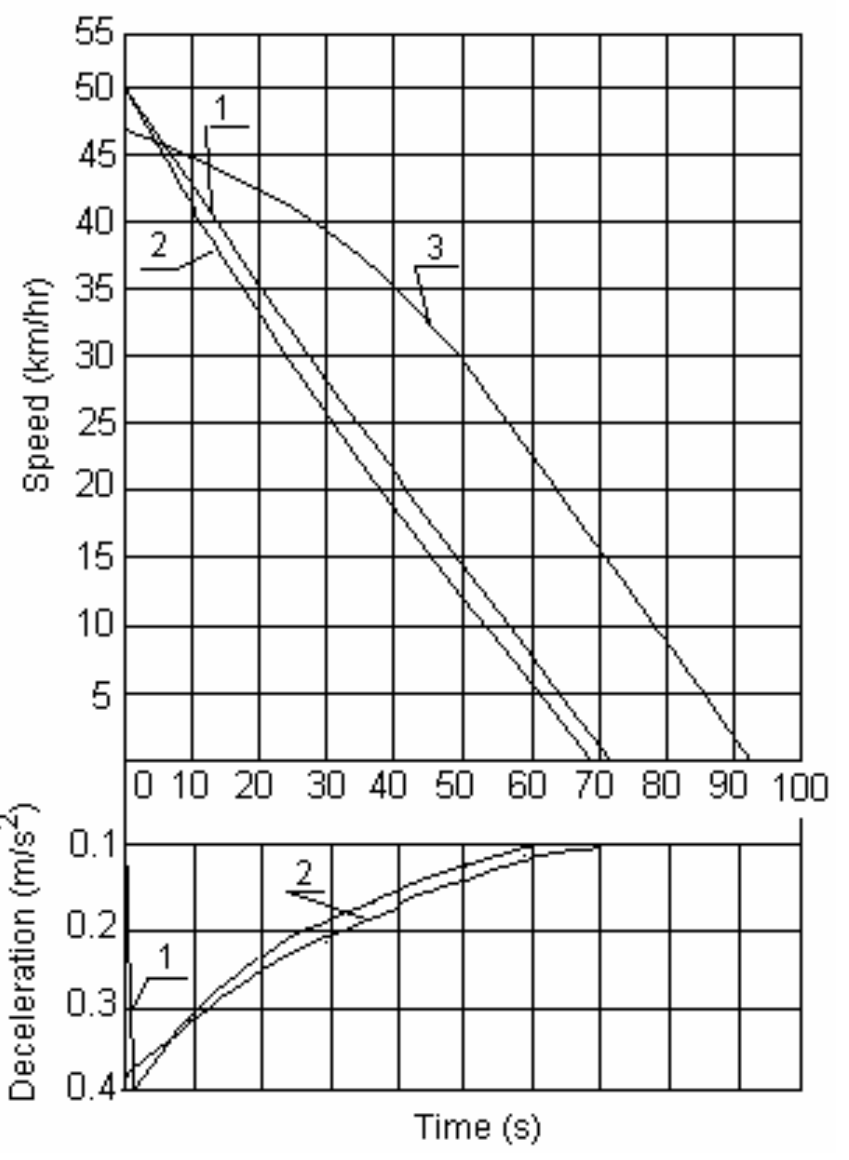

Fig. (9). The experimental and the computed time-relationships of speed and deceleration during the tram-car braking process caused by the action of two magnetic rail brakes and two eddy-current brakes. 1 - the experimental relationship relating to the action of the eddy-current brakes; 2 - the computed relationship relating to the action of the eddy-current brakes; 3 - the experimental relationship relating to the action of the magnetic rail brakes.

\section{Side view}
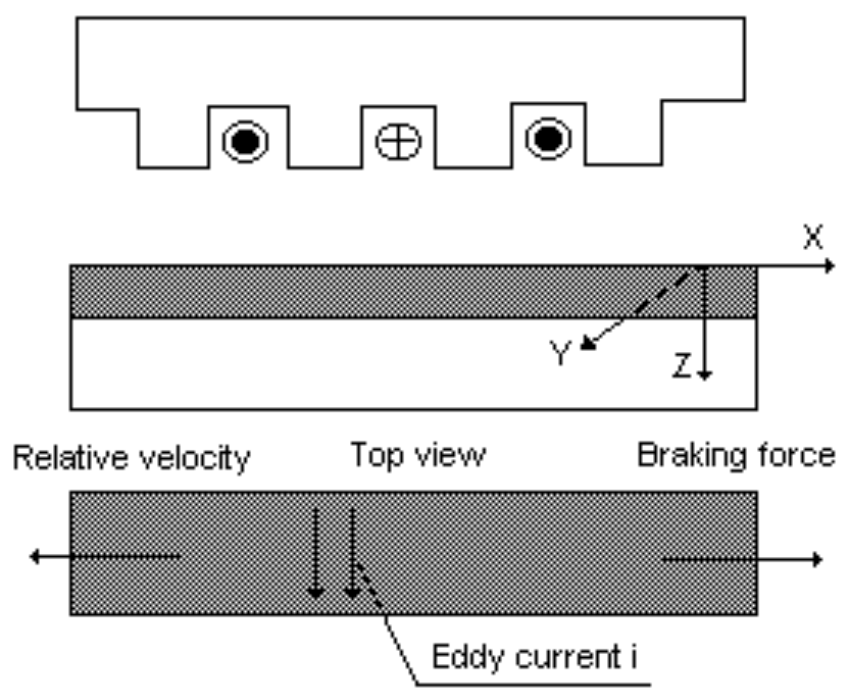

Fig. (10). Structural drawing of the eddy-current brake with coordinate fixed to a point on the rail; the eddy current is directed to the $\mathrm{Y}$ direction. 
Table 3. The Electrical, Magnetic and Mechanical Parameters of Eddy-Current Brake Computations

\begin{tabular}{|l|c|}
\hline \multicolumn{1}{|c|}{ Parameter (SI unit) } & Value \\
\hline \hline Magnetic Excitation $(\mathrm{Q}, \mathrm{AT})$ & $\mathbf{1 5 0 0 0}$ \\
\hline Pole Pitch $(\tau, \mathrm{m})$ & $\mathbf{0 . 0 9}$ \\
\hline Pole Width in x-direction $(2 \mathrm{a}, \mathrm{m})$ & $\mathbf{0 . 0 6}$ \\
\hline Air-gap $(\mathrm{g}$ m) & $\mathbf{0 . 0 0 7}$ \\
\hline Electrical conductivity of rail $\left(\sigma, \Omega^{-1} \mathrm{~m}^{-1}\right)$ & $\mathbf{2 \cdot 1 0 ^ { 6 }}$ \\
\hline Rail width $(\mathrm{L}, \mathrm{m})$ & $\mathbf{0 . 1 2}$ \\
\hline Effective rail width $\left(\mathbf{b}_{\mathbf{m}}, \mathbf{m}\right)$ & $\mathbf{0 . 0 6}$ \\
\hline
\end{tabular}

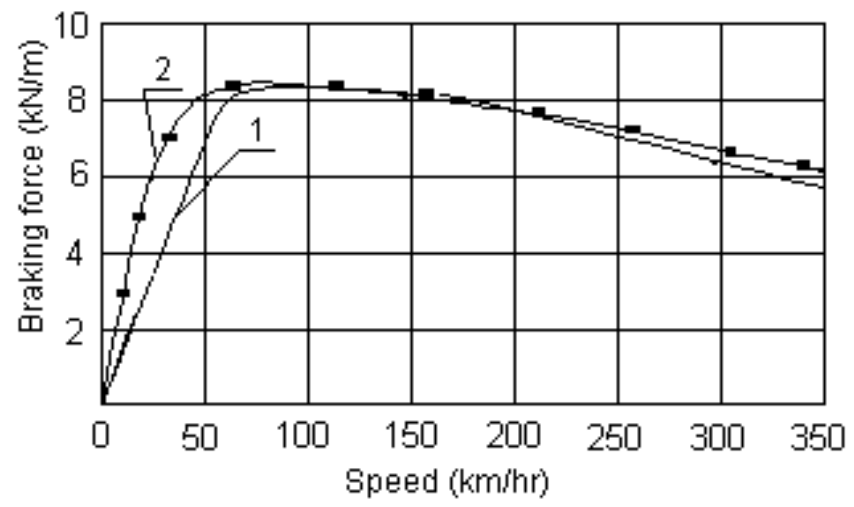

Fig. (11). Comparison on the braking force between the computed (1) and experimental (2) results; experimental results are based upon the data from [4].

\section{THE ANALYSIS OF RAIL BRAKE STRUCTURES}

The devised computer engineering analysis procedure for both magnetic rail brake and eddy-current brake structures demonstrates good agreement between computed and experimental data available. This suggests the use of the procedure for some brake structure analysis that directed on a search for the variant having best operating brake characteristics.

As mentioned above, it is required of a rail brake that it shall profitably brake a railroad vehicle and that its braking force shall not depend on adhesion force between the wheel and the rail, moreover, the braking force shall be greater than the adhesion force.

Such a brake must:

1. operate profitably throughout the range of acceptable speeds, even with zero speed (a parking brake),

2. be of minimum mass,

3. be easy to control,

4. be reliable "absolutely", that is, provide an emergency braking action even in case of failure of all train power delivery systems.

Let us consider magnetic rail brakes and eddy-current brakes from this standpoint.

Following are the results of computations with the use of electrical and magnetic parameters given in Table 2. Good agreement between experimental and computed data allows the use of results of computations as the basis for the brake analysis.

\section{A Magnetic Rail Brake}

A magnetic rail brake is lowered in the direction of the adjacent rail over which the railroad vehicle is travelling, and under the excitation of a coil or of permanent magnet pieces the brake shoes are held firmly against the head of the rail. In this situation the adhesion force is the result of the attraction between the brake and the rail.

The performance. The performance of the magnetic rail brake is governed by the attraction force $F_{N}$ that is in direct proportion to the induction of the magnetic field $B$ at the contact area of the brake and the rail and to this contact area value $S$ :

$$
F_{N}=k \times B^{2} \times S
$$

where: $B$ is the induction of the magnetic field,

$S$ is the value of the contact area,

$k$ is the proportionality coefficient.

Therefore, in order to raise the magnetic rail brake performance the designer has to raise two specified parameters.

The magnetic saturation of both the magnet assembly armature of the brake and the steel of the rail bound to the rise of the induction of the magnetic field. It is also bounded by the magnetic field source power. As magnetic field sources we consider electromagnets and permanent magnet pieces.

The rise of the contact area is bounded by the permissible brake length and by the profile and the dimensions of the rail.

The range of speeds. A magnetic rail brake operates profitably throughout a speed range determined by the speed-relationship of the friction coefficient. One can see from the formula (1) and from [8] that the value of the braking force of a magnetic rail brake is halved even at the speed value equal to $50 \mathrm{~km} / \mathrm{hr}$. This has led many people to believe that a magnetic rail brake may be used at speed values up to $50 \mathrm{~km} / \mathrm{hr}$.

A parking brake and an emergency brake. A magnetic rail brake built up of permanent magnet pieces may be used as a parking brake and as an emergency brake, in particular, in the event of other braking systems failure (if the construction arrangement allows for the lowering in the direction of the adjacent rail).

The braking force. Fig. (12) shows the computed speedrelationships of braking force per meter for multipole magnetic rail brakes exciting via electric coils (curves $2,3,4$ ) at the different pole dimensions lengthwise of the rail and the constant pole separation equal to $90 \mathrm{~mm}$. The curve 1 in Fig. (12) relates to the multipole magnetic rail brake containing permanent magnet pieces with the pole separation equal to $10 \mathrm{~mm}$. The magnetic field induction value at the rail surface is equal to $1.5 \mathrm{~T}$ for all curves; therefore, the differences in curves $1,2,3,4$ are attributable only to the differences in values of the contact area of the brake and the rail. 


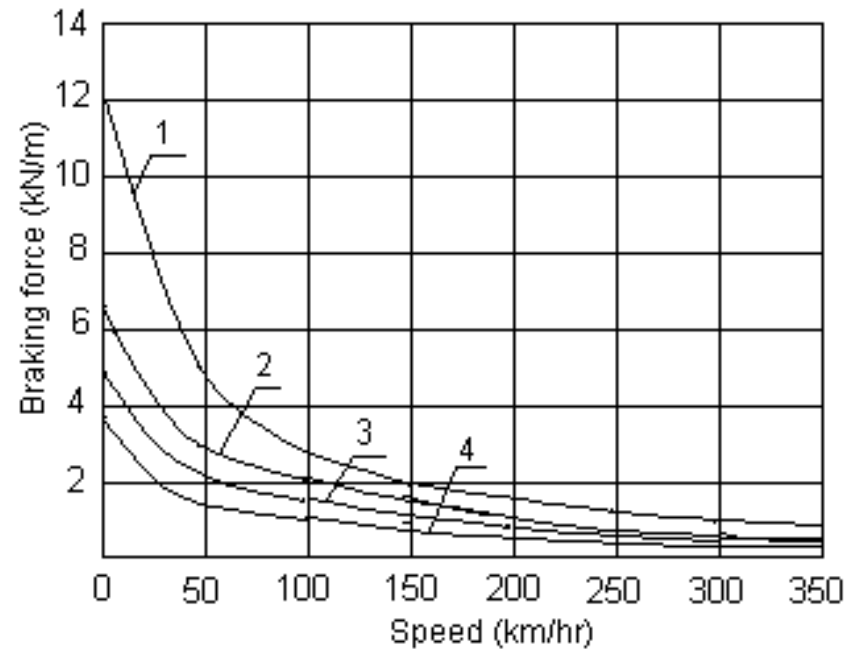

Fig. (12). The speed-relationships of braking force per meter of the brake length computed for magnetic rail brakes exciting via electric coils $(2,3,4)$ and via permanent magnets (1). Pole separation values: $1-10 \mathrm{~mm}, 2,3,4-90 \mathrm{~mm}$. Pole dimension length of the rail values: $1-80 \mathrm{~mm}, 2-80 \mathrm{~mm}, 3-60 \mathrm{~mm}, 4-40 \mathrm{~mm}$.

\section{An Eddy-Current Rail Brake}

The function of an eddy-current brake is based on the law of electromagnetic induction. An eddy-current brake consists of an iron yoke with several pole cores. Electric coils or permanent magnet pieces magnetically excite the brake, so that magnetic north and south poles are generated in an alternating manner. When the excited eddy-current brake is moved along the rail - that is, during a braking, - electromagnetic fields and eddy currents are generated as a result of the changes of the time rate of flow. The secondary magnetic field caused by the eddy currents is opposed to the magnetic field of the brake. The resulting horizontal force component, which acts opposite to the travelling direction, is the braking force.

An eddy-current rail brake is operable with the contact with the rail as with the air gap between the brake and the rail.

The magnetic field distribution and the induction value within the head of the rail, the electric conduction and magnetic properties of rail material, and the speed value of a vehicle control the magnetic rail brake performance.

The distribution and the induction value of the magnetic field within the head of the rail depend on

1. the number of pairs of magnet assembly poles,

2. the dimension of a pole and the value of the pole separation,

3. the magnetic characteristics of the magnetic field source,

4. the magnetic field source type, namely, is it an electromagnet or a assembly built up from permanent magnet pieces,

5. the magnetic properties of rail material.

The electric conduction, the magnetic properties of rail material, the magnetic field distribution, and the speed of a vehicle are responsible for the size of the region of the head of the rail, where eddy current is induced, and for this eddy current value.

There is no one-to-one correspondence between the dimension of a magnet pole, the number of pole pairs, and the magnet induction value, on the one hand, and the braking force value, on the other hand, for an eddy-current brake. It is evident from Figs. (13,14) where computed speedrelationship of braking force curves for an eddy-current brake are presented at different pole dimensions length of the rail and different values of the constant pole separation. All the calculations are performed for magnet assemblies that provide the magnet field induction value $1.5 \mathrm{~T}$ at the head of the rail in case of zero speed value.

Fig. (13) gives braking force per meter of the brake length referred to the pole dimension length of the rail from 40 to $120 \mathrm{~mm}$ and the value of the constant pole separation equal to $90 \mathrm{~mm}$. Specified structure parameters are typical for electromagnet eddy-current brakes.

One can see from Fig. (13) that the braking force grows significantly as the pole dimension lengthwise of the rail increases from $40 \mathrm{~mm}$ to $80 \mathrm{~mm}$. The braking force is approximately constant as the pole dimension increases from $80 \mathrm{~mm}$ to $100 \mathrm{~mm}$. If the pole dimension goes greater than $100 \mathrm{~mm}$ the braking force decreases rapidly.

As the pole dimension increases from 40 to $60 \mathrm{~mm}$, a maximum of braking force transfers slowly to the lesser speed values interval because the superseding of magnetic field of the magnet assembly by magnetic field of the eddy current has a more profound effect. On further pole dimension increase the superseding mentioned affects significantly with greater speed values due to changed eddy current trajectories in case of long poles (it is concerned, among other things, with the dimension of the head of the rail). A maximum of braking force transfers to the greater speed values interval as the pole dimension decreases.

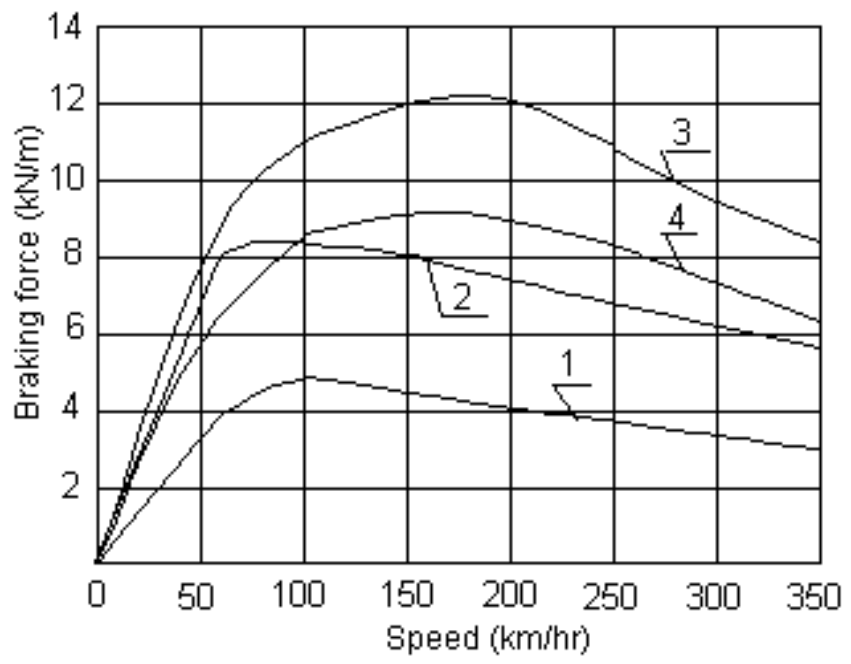

Fig. (13). The speed-relationships of braking force per meter of the brake length computed for electromagnetic eddy-current brakes. Pole dimension length of the rail values: $1-40 \mathrm{~mm}, 2-60 \mathrm{~mm}$, $3-80$ and $100 \mathrm{~mm}, 4-120 \mathrm{~mm}$.

Fig. (14) gives braking force per meter of the brake length referred to the pole dimension lengthwise of the rail 
from $40 \mathrm{~mm}$ to $100 \mathrm{~mm}$ and the constant pole separation equal to $10 \mathrm{~mm}$. Specified structure parameters may be realized only on magnet assemblies containing permanent magnet pieces.

One can see from Fig. (14) that as the pole dimension lengthwise of the rail increases from 40 to $60 \mathrm{~mm}$, the braking force grows rapidly and a maximum of braking force transfers to the lesser speed values interval. With the pole dimension equal to $60 \mathrm{~mm}$ the superseding of magnetic field of the magnet assembly by magnetic field of the eddy current has a profound effect. It shows up in the rapid decrease of the braking force at speed values in excess of $100 \mathrm{~km} / \mathrm{hr}$. With pole dimension increases from $60 \mathrm{~mm}$ to $100 \mathrm{~mm}$ the maximum braking force value decreases and transfers to the greater speed values interval.

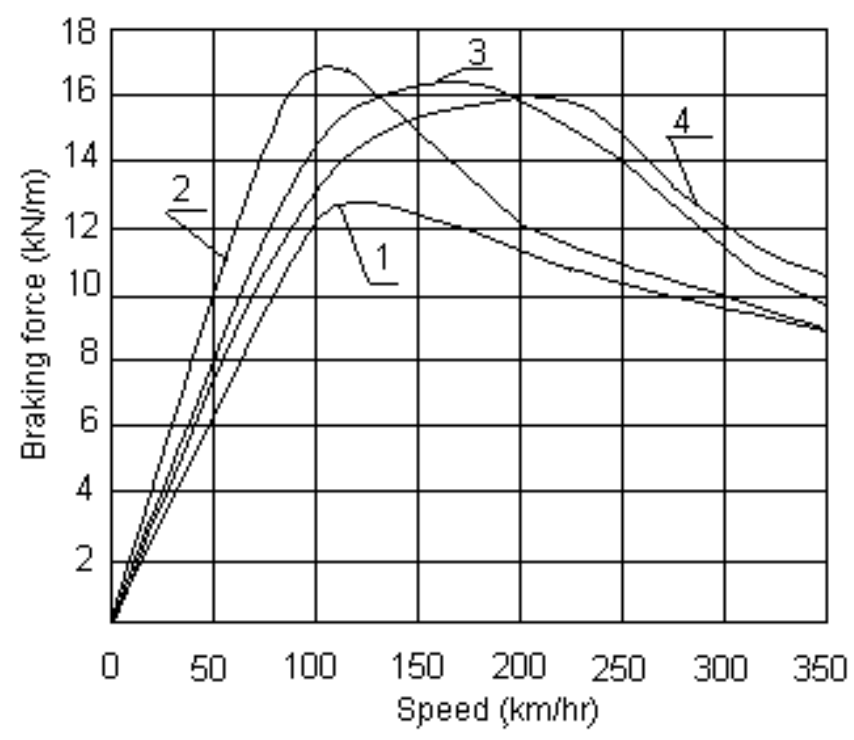

Fig. (14). The speed-relationships of braking force per meter of the brake length computed for eddy-current brakes built up from permanent magnet pieces. Pole dimension lengthwise of the rail values: $1-40 \mathrm{~mm}, 2-60 \mathrm{~mm}, 3-80 \mathrm{~mm}, 4-100 \mathrm{~mm}$.

One can see from Figs. $(\mathbf{1 3}, \mathbf{1 4})$ that the best performance of an eddy-current brake may be realized at the range of speed values from 50 to $250 \mathrm{~km} / \mathrm{hr}$ and the performance is somewhat lower if the speed value increases up to 350 $\mathrm{km} / \mathrm{hr}$.

From the aforesaid it follows that the set of construction requirements imposed on an eddy-current brake is more "powerful" than that imposed on a magnetic rail brake.

It includes:

1. the need for magnet poles polarity alternating,

2. the fixed magnetic field induction value,

3. the fixed pole dimension,

4. the fixed value of the constant pole separation.

These requirements are not in conflict with corresponding requirements imposed on a magnetic rail brake. On the one hand, when a magnetic rail brake is attracted to the rail then a leakage flux decreases and magnetic induction of the brake increases. On the other hand, if an eddy-current rail brake has small pole separation then the value of the contact area of the brake and the rail differs from the greatest possible value nothing more than $10-15 \%$.

Fig. (15) shows the computed characteristics of the electromagnetic brake that acts both as a magnetic rail brake and as an eddy-current brake at a time.

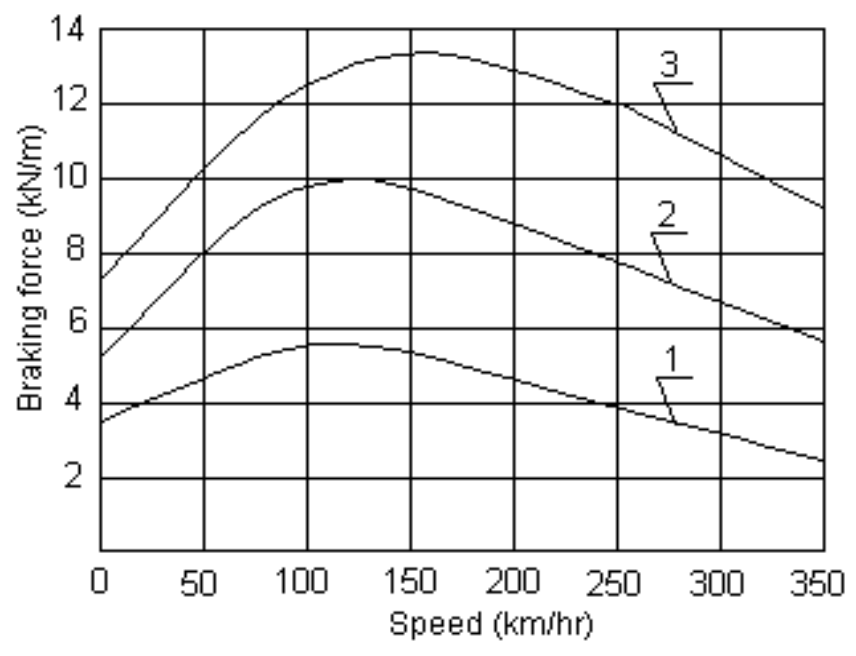

Fig. (15). The speed-relationships of braking force per meter of the brake length computed for electromagnetic brakes that act both as a magnetic rail brake and as an eddy-current brake at time. Pole dimension lengthwise of the rail values: $1-40 \mathrm{~mm}, 2-60 \mathrm{~mm}, 3$ - $80 \mathrm{~mm}$. The constant pole separation value: $90 \mathrm{~mm}$.

Fig. (16) shows the computed characteristics of the combined magnetic rail brake and eddy-current brake that is built up from permanent magnet pieces.

It is most pronounced in Fig. (16) that a brake combining a magnetic rail brake and an eddy-current brake and is built up from permanent magnet pieces would operate profitably throughout the whole range of acceptable speeds. Such a brake could operate as a parking brake. Besides, such a brake, and no other, would provide a profitably emergency braking action in case of failure of other train brakes.

Figs. $(15,16)$ demonstrate that a permanent magnet structure is better than a structure based on electromagnets for brakes that combine both magnetic rail brake and eddycurrent brake. When considering both the brake with electromagnets and the brake with permanent magnet pieces it was assumed that a magnetic field source generates the induction $1.5 \mathrm{~T}$ in the interior of the head of the rail. However, such pictures are not representative of the energy problem. The energy component determines on the one hand the efficiency and on the other hand the mass and dimensions of brakes. Let us next show that the use of permanent magnet assemblies is more profitably than the use of electromagnets from the energy standpoint.

Indeed, let us consider a ring-type permanent magnet piece of the internal diameter $D_{1}$, the external diameter $D_{2}$, and the length $L$ wherein the magnetization value is $J$.

The magnetization is

$J=\frac{M}{V}$,

where: $M$ is the magnetic moment,

$V$ is the volume of permanent magnet piece. 
It is known that $M=I \times S$,

where $I$ is the ring current,

$S$ is the area enclosed by ring current.

Hence it follows:

$$
\begin{aligned}
& J=\frac{M}{V}=\frac{I \times S}{V}= \\
& =\frac{j \times \frac{\left(D_{2}-D_{1}\right)}{2} \times L \times \frac{\pi}{4} \times\left(\frac{D_{2}+D_{1}}{2}\right)^{2}}{L \times \frac{\pi}{4} \times\left(D_{2}^{2}-D_{1}^{2}\right)}=j \times \frac{D_{m}}{4}
\end{aligned}
$$

where: $j$ is the current density, and

$D_{m}=\left(D_{2}+D_{1}\right) / 2$.

So the relationship holds between the current density of an equivalent electromagnet and the magnetization of a permanent magnet piece:

$$
J=j \times \frac{D}{4}
$$

where $D$ is the characteristic dimension of the electromagnet.

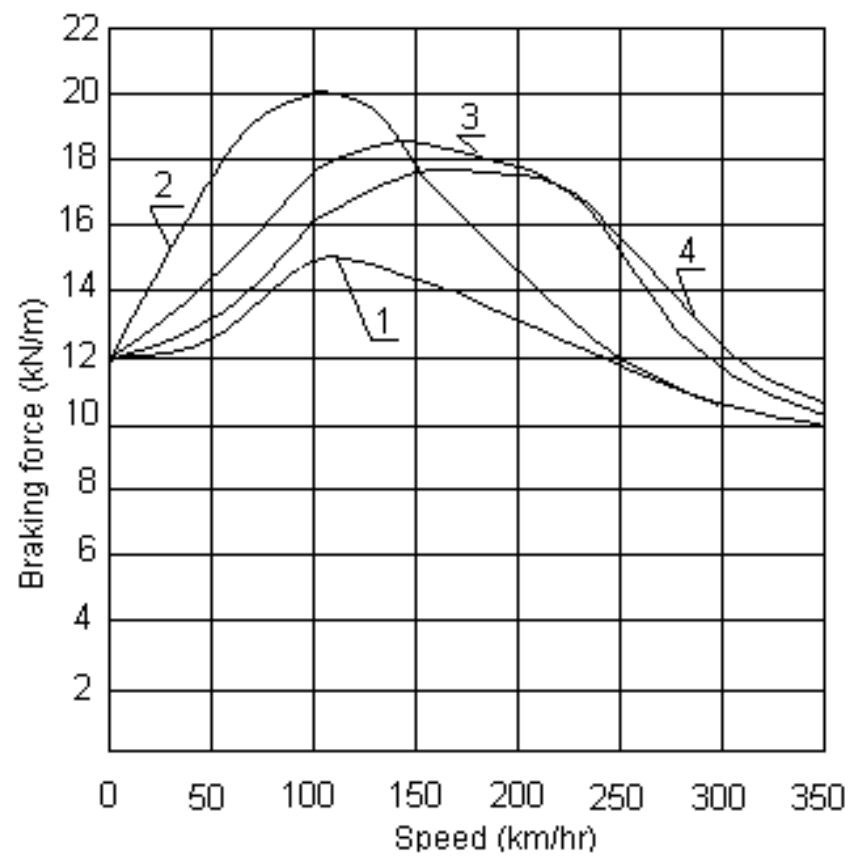

Fig. (16). The speed-relationships of braking force per meter of the brake length computed for brakes with combined magnetic rail brake and eddy-current brake structure built up from permanent magnet pieces. Pole dimension length of the rail values: $1-40$ $\mathrm{mm}, 2-60 \mathrm{~mm}, 3-80 \mathrm{~mm}, 4-100 \mathrm{~mm}$.

Both a permanent magnet piece and an electromagnet may be used as a brake magnetic field source.

The relationship (3) allows to compare these two magnetic field sources in the example of the head of the rail diameter $D=7 \cdot 10^{-2} \mathrm{~m}$.

Table 4 contains current density values for electromagnets which are equivalent to permanent magnet pieces.

There is no way to construct rail brake electromagnets of such current density values and therefore it is apparent that brakes with electromagnets (Figs. 13,15) are less efficient than brakes with permanent magnet structures (Figs. 14,16).

Table 4. Current Density of an Equivalent Electromagnet and the Magnetization of a Permanent Magnet Piece

\begin{tabular}{|l|c|c|c|}
\hline & Ferrite & SmCo $_{5}$ & Nd-Fe-B \\
\hline \hline $\mathrm{J}, \mathrm{kA} / \mathrm{m}$ & 300 & 600 & 900 \\
\hline $\mathbf{j}, \mathbf{A} / \mathbf{m m}^{2}$ & 15 & 30 & 45 \\
\hline
\end{tabular}

\section{CONCLUSIONS}

The design of high-performance braking systems for high-speed rail transport came to be regarded as a "hottest" industrially important problem. The reason is that the enhancement of speed is liable to rule out the braking distance increase and the reduction in the traffic safety.

The computations performed show that an eddy-current brake built up from permanent magnet pieces and marked by a magnet pole dimension lengthwise of the rail between 70 and $90 \mathrm{~mm}$ and a constant pole separation $10 \mathrm{~mm}$ would give the best brake performance.

A rail brake that combines both magnetic rail brake (with adhesion as the basis for an operation) and eddy-current brake permits profitable braking action through the range of acceptable speeds. Such a brake might be of use as a parking brake and also as an emergency brake in case of failure of other train brakes.

Brakes that combine both magnetic rail brake and eddycurrent brake are characterized by the least feasible mass and dimensions.

It is apparent that magnetic eddy-current rail brakes containing permanent magnet pieces offer several advantages over conventional braking systems. However, some problems center on the switching the brake "on" and "off" and on the control a braking force. Feasible approaches to the switching process and to the emergency lowering the brake in the direction of the adjacent rail are discussed in $[7,1]$.

The examination of the run of the deceleration curves (Figs. 8,9 as examples) suggests that there is a good reason to control a brake under consideration not through the monitoring of the gap size between the brake and the rail but through the monitoring of operation time. The procedure of control the time of the brake is "on" was put through tests involving the action of braking a tram and which worked well.

\section{REFERENCES}

[1] H. Van Oostveen and R. Siezen, "Erfahrungen mit Permanentmagnet-Schienenbremsen", Glasers Annalen, Nr 12, S. 613-617, 1997.

[2] M. Schlabschi and E. Böttcher, "Elektrodynamische Gleisbremsen", Eisenbahningenieur, $\mathrm{Nr}$ 12, S. 858-861, 1995.

[3] M. Hesquet, P. Brochet and S.J. Lee, P. Delsalle, "A linear eddy current braking system defined by finite element method", IEEE Trans. Magn., vol. 35, pp. 1841-1844, May 1999.

[4] P.J. Wang and S.J. Chiueh, "Analysis of eddy-current brakes for high speed railway”, IEEE Trans. Magn., vol. 34, pp. 1237-1239, July 1998 .

[5] A. Podol'skii, "Multipurpose software for solving problems of magnetostatics" (in Russian), Software \& Systems, No 1, pp. 33-38, 1995. 
[6] A. Podol'skii, "On a numerical solution of a case of magnetization of ferromagnetic materials" (in Russian), Electrichestvo, No 8, pp. 80-84, Aug. 1990.

[7] D.Z. Karminsky, M.D. Fokin, O.V. Bescennaya and N.S. Shlyakhov, "Rail brakes with permanent magnets" (in Russian), Vestnik VNIIGT, No 8, pp. 43-45, 1972.

[8] K. Schofield, "Overview of magnetic brakes", Interfleet Technology Ltd Report, No ITLR/T11315/001, May 2002. Available: www.rssb.co.uk/pdf/reports/Research/
[9] W. Schlosser, "Neue Bremssysteme als integraler Bestandteil innovativer Fahrzeugkonzepte", Glasers Annalen, Nr 2/3, S. 121-130, 1997.

[10] A.V. Kunevich, A.V. Podol'skii and I.N. Sidorov, Ferrites. Encyclopaedic guide. Part I. Magnets and magnet assemblies (in Russian). St. Petersburg: Lik Publishing, 2004.

[11] G.A. Riabinin, Ed., Physical quantities handbook (in Russian). St. Petersburg: Soiuz Publishing, 2001.

Received: April 3, 2008

(C) Yigitcanlar et al.; Licensee Bentham Open.

This is an open access article distributed under the terms of the Creative Commons Attribution License (http://creativecommons.org/licenses/by/2.5/), which permits unrestrictive use, distribution, and reproduction in any medium, provided the original work is properly cited. 